\title{
Quantifying the impact of pumping on groundwater heads using observation data and advanced time series analysis
}

\author{
V. Shapoori $^{\mathrm{a}}$, T.J. Peterson ${ }^{\mathrm{a}}$, A.W. Western ${ }^{\mathrm{a}}$ and J. Costelloe ${ }^{\mathrm{a}}$ \\ ${ }^{a}$ Department of Infrastructure Engineering, the University of Melbourne, Parkville, Vic 3010, Australia \\ Email:v.shapoori@pgrad.unimelb.edu.au
}

\begin{abstract}
The dynamics of groundwater levels within unconfined aquifers are often the result of numerous and interacting factors, such as land cover change, climate variability and groundwater pumping. For such unconfined aquifers, estimating the impact from pumping is highly significant for resource management but also very challenging. To date, in Australia, the HARTT multiple linear regression methodology (Ferdowsian et al. 2001) has been widely used to estimate the impact of climate variability on groundwater levels. Recently, transfer function noise (TFN) models have been developed to better link water table dynamics with different types of individual stresses, including pumping (von Asmuth et al. 2002, von Asmuth et al. 2008). Peterson \& Western (2011) advanced the transfer function noise model of von Asmuth et al. (2008), which is hence referred to as SMS-TFN, to account for non-linear unsaturated zone processes by inclusion of a parsimonious vertically lumped soil moisture model. However, despite this model performing very well for non-pumped aquifers, there is little confidence in its ability, or any existing method, to predict the effect of human interventions, such as land use change and pumping, on water table dynamics.
\end{abstract}

This paper proposes a new time series formulation for estimation of the impacts of groundwater pumping. It is based upon standard well hydraulics and is an extension to Peterson \& Western (2011). Herein, the model is described and assessed against existing methods via use of a synthetic MODFLOW study.

A MODFLOW model was constructed to derive groundwater hydrographs produced by known pumping rates in combination with varying climate forcing. The model has the following attributes: specified constant and general head boundaries, three layers, pasture landcover and climate data with different types of pumping wells. The model was used to simulate synthetic groundwater time series from observation bores near the pumping wells. Next, the HARTT model, standard TFN model and modified SMS-TFN model were applied to the synthetic groundwater hydrographs and the pumping impact was estimated. The performance of each model was than assessed by reviewing the modelled pumping contribution against the 'known' pumping. The predictive performance of models was also assessed by split sample calibration, evaluation and calculation of the coefficient of efficiency (COE) and the Akaike information criterion (AIC).

The results of calibration suggested that the modified SMS-TFN model performed better than the other existing methods and produced estimates of groundwater impact very comparable to that estimated within MODFLOW. Moreover, the result of modelling the pumping contribution to head showed that only the modified SMS-TFN correctly modeled the behavior of pumping in groundwater time series. Further work is required to assess this model in more complex scenarios and on non synthetic cases.

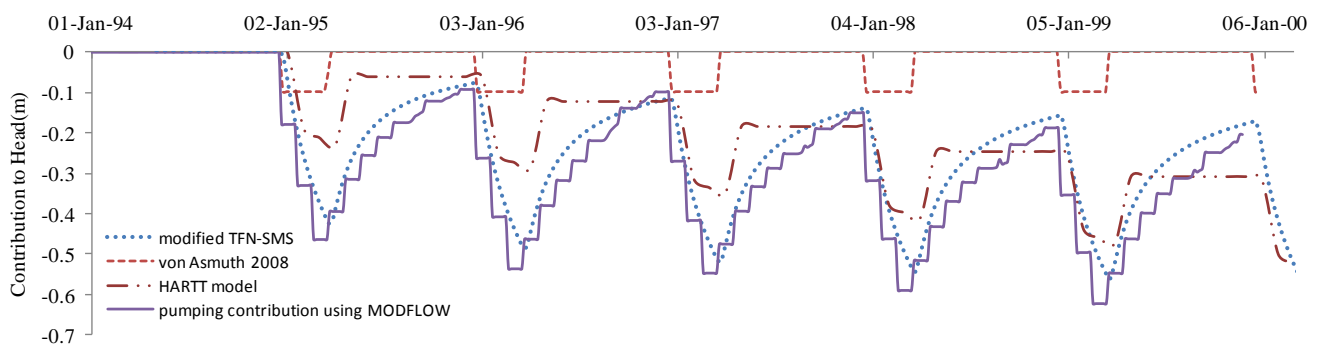

Figure. Result of contribution of pumping to groundwater head

Keywords: groundwater, pumping, time series modelling 


\section{INTRODUCTION}

Variations in groundwater levels within unconfined and confined aquifers are often the result of numerous and interacting factors, such as land cover change, climate variability and groundwater pumping. Estimating the impact from pumping, in comparison with other drivers, is very valuable for resource management but also very challenging.

A variety of methods are used to model water-table dynamics, ranging from spatially explicit, deterministic, numerical physical-mechanistic models, such as MODFLOW, to stochastic approaches, such as Autoregressive Moving Average (ARMA). In most cases where there is little information available about the properties of the catchment, time series analysis is a convenient and less complicated approach that can play a substantial role in investigating the effects of climate and human interventions in groundwater head fluctuations. Because few assumptions are required, time series analysis is usually more accurate than other complex physical models (Kim et al.2005, von Asmuth et al. 2008). To date, in Australia, the multiple linear regression Hydrograph Analysis methodology (HARTT), (Ferdowsian et al. 2001) has been widely used to estimate the impact of climate change or human intervention, such as landuse change, on groundwater levels (Ferdowsian et al. 2002, CSIRO 2009, Yihdego et al.2011, Peterson \& Western 2011).

Transfer function noise modelling is a popular time series approach used in research studies and can be used to model the dynamic behaviour of a wide range of hydrologic variables, including time series of groundwater head. The model can predict the future behaviour of the phenomena and its uncertainty. The original concept of this analysis technique comes from statistical analysis published by Box and Jenkins (1970). However, in that model, there are two important limitations, Firstly the observations of input (such as climate data) and output (such as groundwater table) need to be measured at equally spaced time intervals. This is limiting because in most hydrological time series, the measurements have been collected at irregular intervals. Secondly, the TFN model is limited to linear processes. Recently, transfer function noise (TFN) models have been developed to better link water table dynamics with different types of individual stresses, including pumping (von Asmuth et al. 2002; von Asmuth \& Bierkens 2005 , von Asmuth et al. 2008). This technique can work with different observation frequencies and irregular time intervals and the climate data can be first and second order non-stationary, which is very useful for climate change investigations where stationarity assumptions can't be made. However, we show here that von Asmuth's models were poor for decomposing the dynamics of groundwater tables into its contributions, especially pumping.

Peterson \& Western (2011) advanced the transfer function noise model of von Asmuth et al. (2008), which is hence referred to as SMS-TFN, to account for non-linear hydrological processes by inclusion of a parsimonious vertically lumped soil moisture model (Siriwardena et al. 2011). However, despite this model performing very well for non-pumped aquifers, there is little confidence in its ability, or any existing timeseries analysis method, to predict the effect of human interventions on water table dynamics.

This paper proposes a new time series formulation for estimation of the impacts of pumping. It is based upon standard well hydraulics and is an extension to Peterson \& Western (2011). It also undertakes a controlled assessment of the ability of a range of time series models to represent the impacts of pumping by applying them to time series from a synthetic aquifer simulated with MODFLOW. The paper is organised as follows. The transfer function noise and HARTT models are described followed by the synthetic aquifer model. Then the time series models are used to decompose the hydrographs into various contributions and predictions and decomposition performance is assessed against existing methods and finally comparisons are made.

\section{METHODOLOGY:}

\subsection{Transfer function noise model (TFN):}

In the original TFN model, head is simulated as the linear sum of three components which are attributed to inputs and a noise component. In continuous time, the dynamic relationship between observed groundwater table and climate data is described as below:

$h_{t}=h_{t}^{*}+n_{t}+d$

$\mathrm{h}_{\mathrm{t}}^{*}=\sum_{\mathrm{i}=1}^{\mathrm{n}}\left(\int_{-\infty}^{\mathrm{t}} \theta_{\mathrm{i}}(\mathrm{t}-\tau) \mathrm{R}_{\mathrm{i}}(\tau) \mathrm{d} \tau\right)$

Where: $h_{t}$ the simulated groundwater level at time step $t[L] ; h_{t}^{*}$ the climate contribution to the groundwater level at time step $\mathrm{t}$ attributed to all stresses[L]; $\mathrm{n}_{\mathrm{t}}$ the residual series; $\mathrm{d}$ the local drainage relative to some reference level [L]; $\theta_{i}$ the weighting or impulse response function of stress $i$; $R_{i}$ the value of stress $i$. 
The most important part of the transfer noise function is the impulse response function and it specifies the way in which the groundwater table responds to an instantaneous change of stresses, such as precipitation or pumping. The Pearson type III distribution, multiplied by A parameter, was chosen for precipitation and evapotranspiration types of stresses, which is shown as follow (von Asmuth et al. 2008):

$\theta_{\mathrm{p} \& e}(\mathrm{t})=\mathrm{A} \frac{\mathrm{a}^{\mathrm{n}} \mathrm{t}^{\mathrm{n}-1} \exp (-\mathrm{at})}{\Gamma(\mathrm{n})}$

Where $\mathrm{A}, \mathrm{a}, \mathrm{n}$ are parameters and $\Gamma$ is a gamma distribution. The main advantage of this type of response function is that it can consider the delay time between precipitation and recharge to the groundwater table. The A parameter has been chosen as the scalar to transform the stress into groundwater level series.

For pumping stresses, Asmuth et al. (2008) have adopted the Hantush formula for a leaky aquifer and the response function has been defined by the derivative of the response function with respect to time. In this study for the sake of simplicity the well formula of Ferris and Knowles (1963) has been chosen. The Ferris and Knowles formula assumes a confined aquifer and measures the response of the head to the injection of a slug of water of volume $\mathrm{V}$ at $\mathrm{t}=0$. The difference between the groundwater elevation before and after injection at any time is described as bellow:

$\mathrm{D}=-\frac{\mathrm{v}}{4 \pi \mathrm{Tt}} \exp \left(-\frac{\mathrm{r}^{2} \mathrm{~s}}{4 \mathrm{Tt}}\right)$

The new impulse function, which is derived from the Ferris and Knowles formula, is defined as below:

$\theta_{\mathrm{w}}(\mathrm{t})=-\frac{\alpha}{\gamma \mathrm{t}} \exp \left(-\frac{\beta}{\gamma \mathrm{t}}\right)$

The $\gamma$ and $\beta$ parameters in this equation represents the transmissivity and a proportion of the squared distance between the pumping well and observation bore. In Figure 1, a selection of impulse response curves for different values of $\beta$ are shown. Generally, this impulse function can characterise curves from a steep slope to Gaussian curve. This equation includes the time lag between the start time of pumping and the effect of that in the groundwater time series, which becomes important as the distance between the well and observation bore increases. However, in this equation, $\alpha, \beta, \gamma$ are parameters that no longer have a physical description except for the cases where Ferris and Knowles assumptions are satisfied.

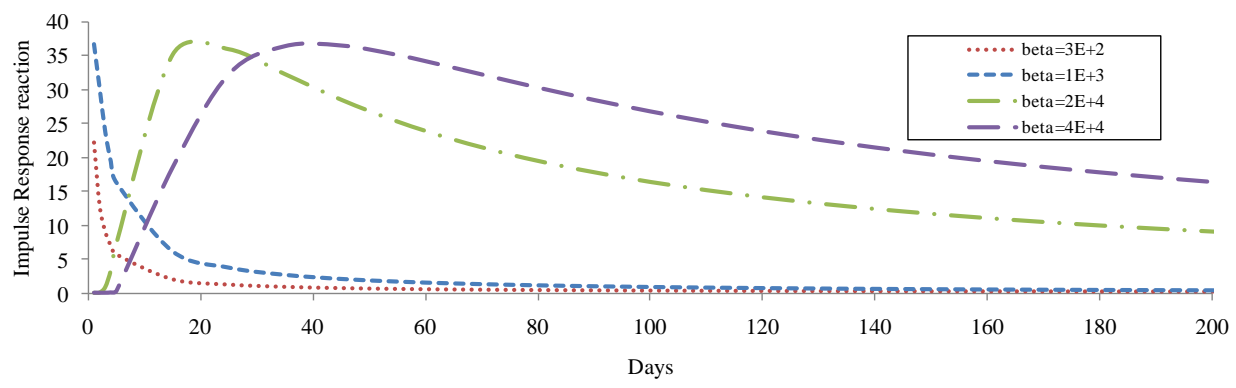

Figure 1. The different types of pumping impulse response functions $(\alpha=\beta \times 100, \gamma=1000)$

To represent the filtering of the climate stresses by the unsaturated zone, Peterson \& Western (2011) added a non-linear filter to the model, consisting of a vertically lumped soil moisture model. This model was used to derive an estimate of infiltration or recharge which replaced precipitation:

$\mathrm{S}_{\mathrm{t}}=\mathrm{S}_{\mathrm{t}-1}+\min \left(\mathrm{K}_{\text {infilt }}, \mathrm{P}_{\mathrm{t}}\right)-\mathrm{f}_{\mathrm{E}} \frac{\mathrm{S}_{\mathrm{t}-1}}{\mathrm{~S}_{\mathrm{cap}}} \mathrm{Et}$

Where $S_{\text {cap }}[\mathrm{L}]$ is a parameter for soil moisture storage capacity; $\mathrm{S}_{\mathrm{t}}[\mathrm{L}]$ is the soil moisture at time $\mathrm{t} ; \mathrm{S}_{\mathrm{t}-1}$ is the soil moisture at time $\mathrm{t}-1 ; \mathrm{f}_{\mathrm{E}}$ is a parameter for scaling the areal potential evapotranspiration (APET); $\mathrm{K}_{\text {infilt }}\left[\mathrm{LT}^{-1}\right]$ is a parameter for the maximum infiltration rate and $\mathrm{P}_{\mathrm{t}}$ is precipitation. In order to incorporate the soil moisture component into the TFN model, two modifications were made by Peterson \& Western (2011): 1) replacing the precipitation with the free-drainage recharge estimate; and 2) scaling $E_{t}$ by the soil moisture deficit. The overall equation which has been used in this study is shown below. The first and second term in equation 7 is based on Peterson \& Western (2011) and third term is added in this study.

$h_{t}^{*}=\int_{t}^{-\infty}\left(\frac{s_{t}}{s_{\text {cap }}}\right)^{b} \theta_{p} d \tau-\int_{t}^{-\infty} E_{t}\left(1-\frac{s_{t}}{s_{c a p}}\right) \theta_{p}(t-\tau) d \tau-\int_{t}^{-\infty} w \theta_{w}(t-\tau) d \tau+n_{t}+d$ 
In terms of residuals, the innovation series is calculated based on subtraction of the exponential noise components of previous time steps from the current time step residuals.

$\mathrm{v}_{(\mathrm{t})}=\mathrm{n}(\mathrm{t})-\mathrm{e}^{-\mu \Delta \mathrm{t}} \mathrm{n}(\mathrm{t}-\Delta \mathrm{t})$

For all the parameter set $\chi=(A, a, n, \beta, \gamma, \alpha)$, a weighted least squares objective function derived from the square model innovations was adopted and minimised with respect to $\chi$ using the Levenberg-Marquardt multi-start calibration algorithm outlined within Peterson \& Western (2011). Finally, the predictive performance of models will be assessed by the Akaike information criterion (AIC) and Bayes Information Criterion (BIC), the coefficient of efficiency (COE). The AIC and BIC are defined as follow:

$\mathrm{AIC}=-\ln \mathrm{ML}+2 \mathrm{k}(9)$
$\mathrm{BIC}=-\ln \mathrm{ML}+\mathrm{k} \ln (\mathrm{n})$

Where LnML denotes the value of the maximized log likelihood function for a model fitted to a given data set, $\mathrm{k}$ is the number of independently adjusted parameters within the model and $\mathrm{n}$ is number of observation. Generally, the model that gets the minimum value of the AIC or BIC could be selected as the best model. The $\mathrm{COE}$ is calculated as one minus the sum of the absolute squared differences between the predicted and observed groundwater head normalized by the variance of the observed values.

\subsection{HARTT model:}

The HARTT model is a linear regression analysis which represents the effect of atypical rainfall on the underlying trend of the groundwater table and the time delay between rainfall and its impact on groundwater. The simplest version of this regression model is:

$\mathrm{h}_{\mathrm{t}}=\mathrm{a}_{1} \mathrm{AMRR}_{\mathrm{t}-\mathrm{l}}+\mathrm{a}_{2}\left(\mathrm{t}-\mathrm{t}_{0}\right)+\mathrm{a}_{3}$

Where AMRR is monthly cumulative rainfall residual (more detail in Ferdowsian et al. 2002) and $\mathrm{a}_{1}, \mathrm{a}_{2}, \mathrm{a}_{3}$ are parameters. However the model does not include the effects of pumping and seasonal variation in groundwater table. For the purpose of this research, the modified HARTT model used by Peterson \& Western (2011) is also implemented. To represent these possible impacts in the model, two linear sigmoidal terms were added in order to consider the effect of seasonality and a synthetic variable has been defined $\left(\mathrm{W}_{t}\right)$ that takes a value of 1 in periods of pumping and 0 when the pumping has been stopped (similar to effect of land use change in Ferdowsian et al. 2002).

$h_{t}=a_{1} P_{t}-E_{t}\left[a_{2}\left[1+\sin \left(2 \pi F_{t}\right)\right]+a_{3}\left[1+\cos \left(2 \pi F_{t}\right)\right]\right]+a_{4} W_{t}+a_{5} \sum_{t_{0}}^{t} W_{t}++a_{6}\left(t-t_{0}\right)+a_{7}$

Where $h_{t}$ is the groundwater head $[L] ; a_{1}$ to $a_{7}$ are model parameters; $P_{t}$ is the monthly cumulative rainfall residual $\left[\mathrm{LT}^{-1}\right] ; \mathrm{E}_{\mathrm{t}}$ is monthly areal evapotranspiration (APET); $\mathrm{F}_{\mathrm{t}}$ is the fraction of the year at time $\mathrm{t} ; \mathrm{W}_{\mathrm{t}}$ is a binary value for the existence of the pumping during time $t$, and $t 0$ is a reference date.

\section{SYNTHETIC GROUNDWATER TIME SERIES AND MODEL IMPLEMENTATION:}

A model was constructed to produce synthetic groundwater hydrographs resulting from a constant pumping rate $\left(1000 \mathrm{~m}^{3} /\right.$ day) in summer (Jan-March). In Table 1 and Figure 3 , the physical characteristics of the catchment and the location of pumping well and observation bore have been shown. The model had the following attributes: a simple square catchment with $5 \mathrm{~km}$ width and 0.05 percent slope from middle of catchment to the both sides and $5 \mathrm{~km}$ length and 0.15 percent along the valley, constant head at the end of catchment, three layers with the same hydraulic characteristics, pasture as the landcover. The climate forcing data are Perth airport precipitation and synthetic potential evapotranspiration.

Table1. The physical characteristics of soil layers in MODFLOW model

\begin{tabular}{cccccccc}
\hline Layer & Thickness $(\mathrm{m})$ & $\mathrm{K}_{\mathrm{x}, \mathrm{y}}(\mathrm{m} / \mathrm{s})$ & $\mathrm{K}_{\mathrm{z}}(\mathrm{m} / \mathrm{s})$ & $\mathrm{S}_{\mathrm{y}}$ & $\mathrm{S}_{\mathrm{c}}$ & Porosity & Layer Type \\
\hline 1 & 5 & $1 \times 10^{-5}$ & $1 \times 10^{-6}$ & 0.2 & $1 \times 10^{-5}$ & 0.3 & Unconfined \\
2 & 5 & $1 \times 10^{-5}$ & $1 \times 10^{-6}$ & --- & $1 \times 10^{-5}$ & 0.3 & semiconfined \\
3 & $20-33$ & $1 \times 10^{-5}$ & $1 \times 10^{-6}$ & ---- & $1 \times 10^{-5}$ & 0.3 & semiconfined \\
\hline
\end{tabular}

Recharge values for the model were calculated in Class-U3M-1D software, at the mean depth of 2 metres from ground surface and pasture as landcover with default values in model. To produce plausible recharge rates, the precipitating is scaled by 70 percent. The result of the synthetic groundwater time series from observation bore which is 200 away from pumping wells is shown in Figure 2. 


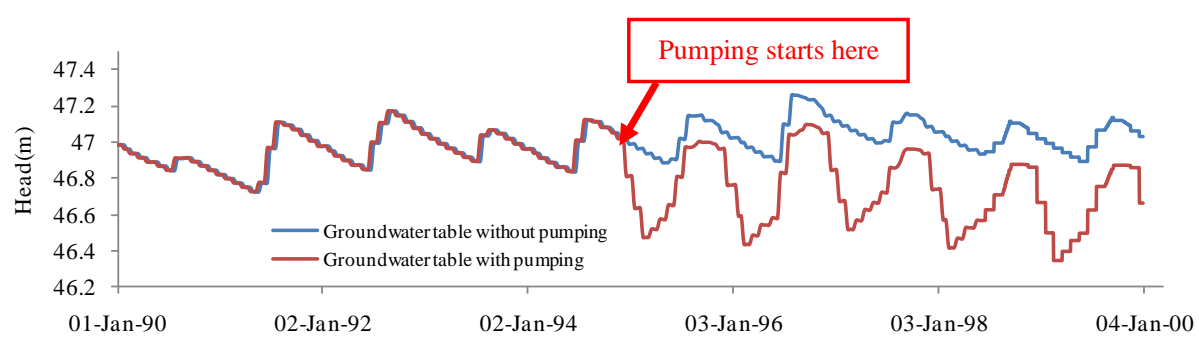

Figure 2.Groundwater tables in bore with and without the effect of pumping

To test the time series models, the following models were calibrated to the synthetic groundwater hydrographs and the pumping impact was estimated and assessed: HARTT model with and without inclusion of the effect of evapotranspiration; von Asmuth et al. (2008) model; and modified SMS-TFN model. Each calibrated model was started with 15 initial starts and maximum number of iterations set to 1000. Also the parameter convergence criteria were set to $1 \mathrm{E}-8$. Bore was calibrated to the first seven years of data (19901996) and evaluated on the remaining three years data (1997-1999).

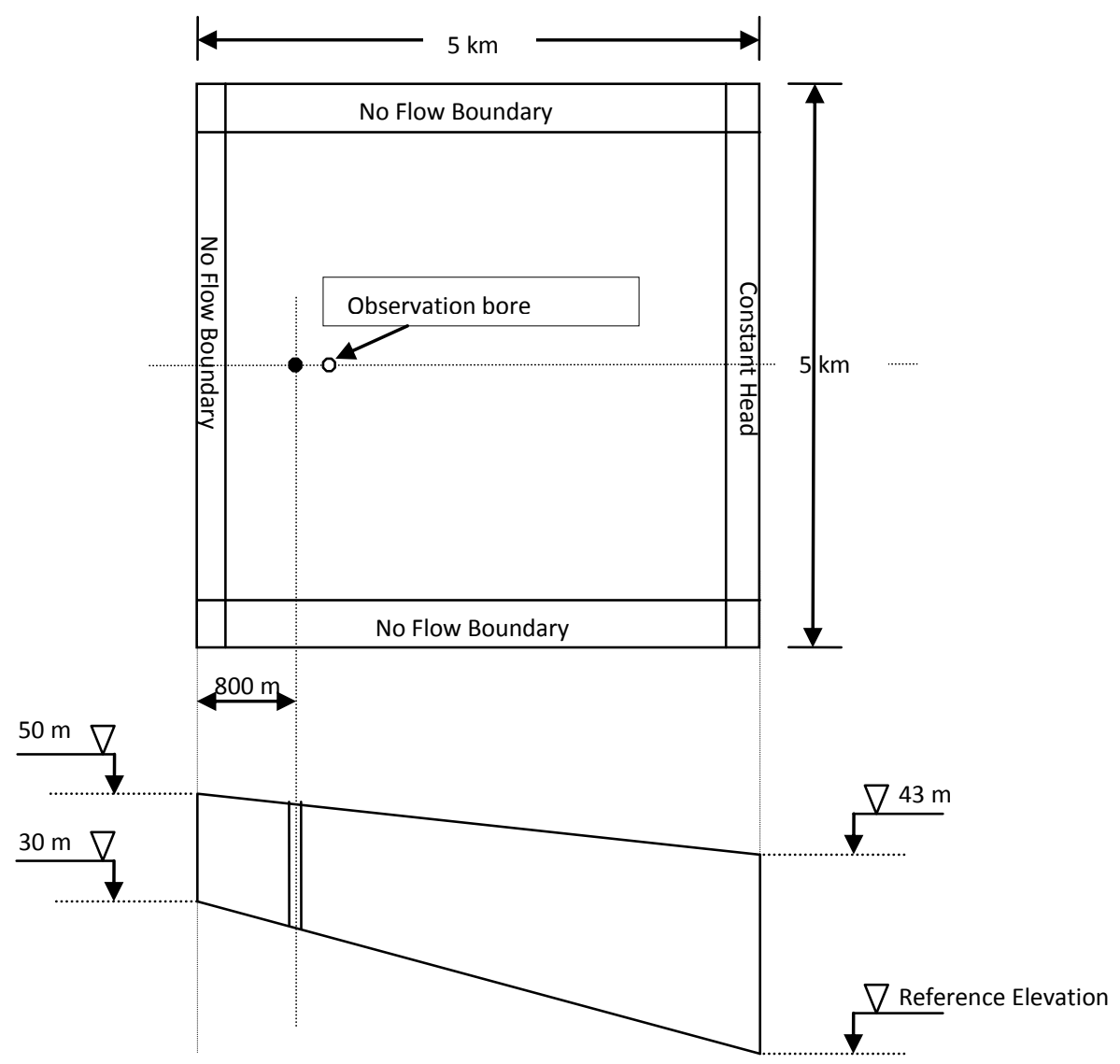

Figure 3. The conceptual catchment dimensions

\section{RESULTS:}

Figures 4 and 5 show the calibration and evaluation results between 1990 and 1999. The result for von Asmuth model shows that the model is approximately fitted to the observation data. In the HARTT model, without inclusion of the sigmoidal terms, it is clear that when pumping stops it simulates the head to immediately recover. However, in the modified HARTT model, this immediate recovery has been attenuated by inclusion of the sigmoidal term (effect of evapotranspiration). 


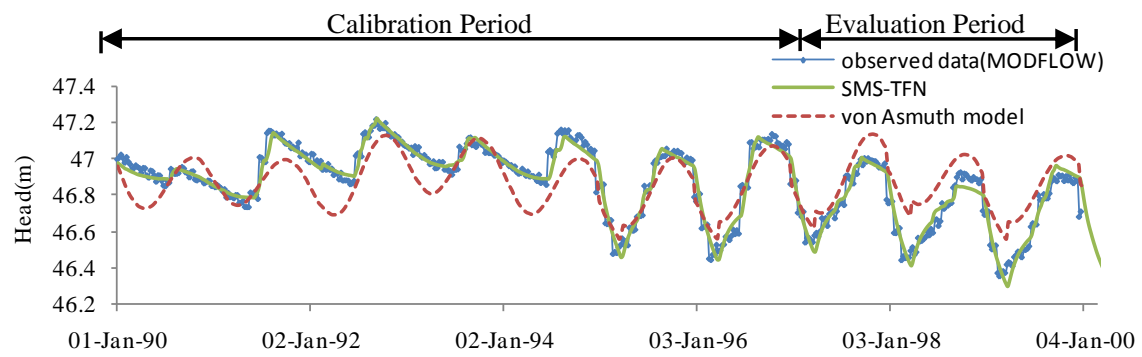

Figure 4. Time series of observed and modelled for bore

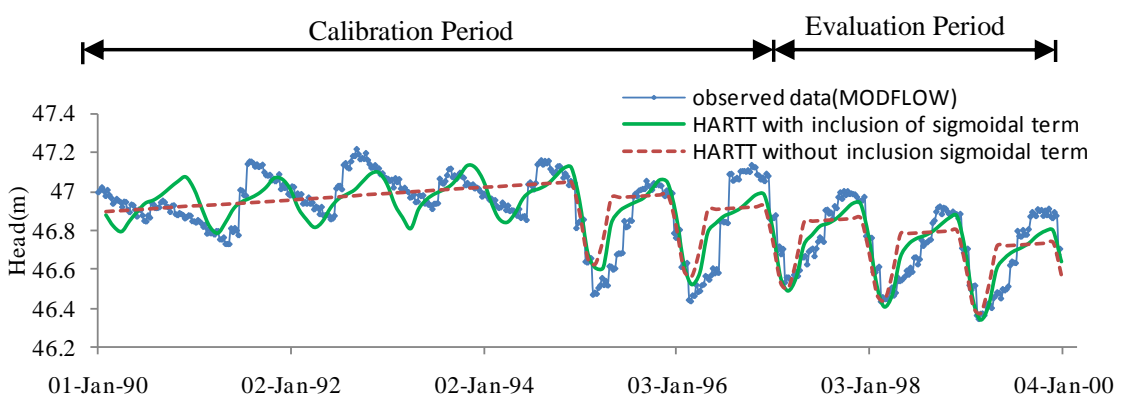

Figure 5. Time series of observed and modelled for bore

Table 2 shows the performance of the model in the calibration and evaluation periods. In SMS-TFN model, the coefficient of efficiency is more than 0.90 , which shows that the model fits the synthetic observation data very well (Figure 4). Although extra parameters have been used for SMS-TFN in comparison with the other two models, the AIC and BIC for the SMS-TFN is consistently less than the AIC for von Asmuth 2008 and HARTT model. However, the performance of the model decreased in evaluation periods (1997-1999), which implies that the calibration periods may not be long enough to identify appropriate models and to estimate the parameters more precisely.

Table 2. The COE and AIC and BIC performance of the calibrations and evaluations (Bold font denoted the model of best calibration and evaluation $\mathrm{COE}$ and BIC and AIC)

\begin{tabular}{ccccccc}
\hline Bore & $\begin{array}{c}\text { COE- } \\
\text { Calibration }\end{array}$ & $\begin{array}{c}\text { COE- } \\
\text { Evaluation }\end{array}$ & $\begin{array}{c}\text { BIC- } \\
\text { Calibration }\end{array}$ & $\begin{array}{c}\text { BIC- } \\
\text { Evaluation }\end{array}$ & $\begin{array}{c}\text { AIC- } \\
\text { Calibration }\end{array}$ & $\begin{array}{c}\text { AIC- } \\
\text { Evaluation }\end{array}$ \\
\hline Model1:Modified HARTT & 0.63 & 0.72 & -4.18 & -3.97 & -4.37 & -4.46 \\
Model2: SMS_TFN & $\mathbf{0 . 9 3}$ & $\mathbf{0 . 8 5}$ & $\mathbf{- 6 . 1 2}$ & $\mathbf{- 4 . 9}$ & $\mathbf{- 6 . 2 4}$ & $-\mathbf{- 5 . 2 3}$ \\
Model3:Von ASmuth (2008) & 0.56 & 0.5 & -4.01 & -3.5 & -4.2 & -4.01 \\
\hline
\end{tabular}
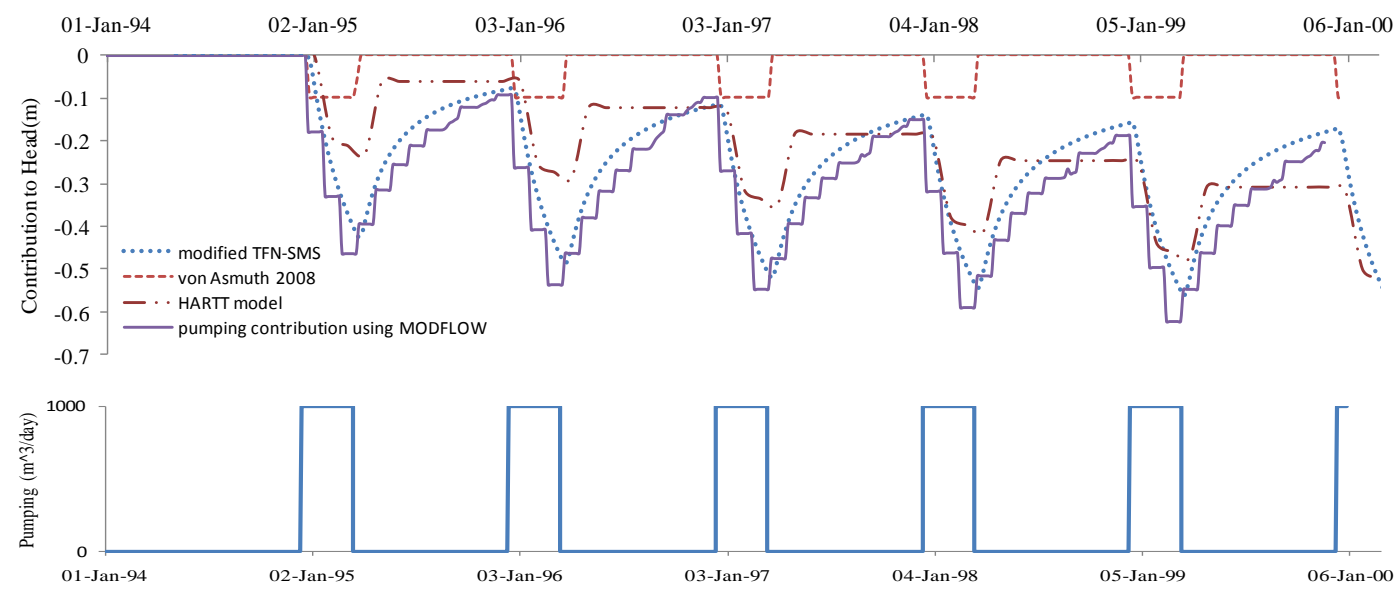

Figure 6. Result of contribution of pumping to groundwater head using HARTT model, Modified SMS-TFN, von Asmuth et al. 2008 model, and the contribution of pumping using MODFLOW 
Figure 6 shows estimated contribution of pumping to the groundwater table from the HARTT model, von Asmuth et al (2008) model and new modified SMS-TFN model. The HARTT model results show that once pumping ceases it fails to simulate any ongoing recovery. The result of the von Asmuth model shows that after pumping ceases, the amount of pumping impact to groundwater heads is zero. As a result, it could not plausibly simulate the effect of pumping on the groundwater table. It seems that the model parameters attributed to pumping contribution have been chosen wrongly and this will tend to add more complexities in the response surface resulting in calibration methods to be less efficient. On the other hand, only the SMSTFN model relatively estimated draw down and recovery magnitude.

Overall, these results suggested that the modified SMS-TFN model performed significantly better than the other existing methods and produced estimates of groundwater impact very comparable to that estimated within MODFLOW.

\section{DISCUSSION AND CONCLUSION:}

In this paper, the TFN-SMS model was extended to include the contribution of pumping on time series analysis. The model was successful in estimating the contribution of pumping to the head fluctuations from a synthetic case study. This provides a promising basis to evaluate and forecast the effects of groundwater pumping on water table elevation. Also, it is concluded that all other models produced results sufficiently poor to warranty their use for application to groundwater pumping.

However in this study, because of the lack of simple analytical equations, the reactions of confined aquifer to pumping was adopted for unconfined aquifer and it may result in reduced predictive performance when the transmissivity during the drawdown is not approximately constant. Also in the real catchment, high uncertainty in the pumping data, the direct relation between pumping extraction and high/low rainfall periods, and complex hydrogeology may have a substantial effect on the outcome of the model. This model is part of ongoing project and it is not tested for situations where many pumping bores are working inside the catchment. Further testing is being undertaken where other complex interactions between surface water and groundwater, which can be important, for example near rivers, exist. Further work is also required to assess this model on non synthetic cases.

\section{References:}

Box,G.E.P. and Jenkins,G.M.(1970). Time Series Analysis:Forcasting and control,San Fransisco, California:Jolden-Day

CSIRO(2009). Groundwater yields in south-west Western Australia:a report to the Australian Government from the CSIRO south-west Western Australi sustainable yeils project,Technical report,Australia

Ferdowsian, R., Pannell,D.J.,McCarron,C.,Ryder,A. and Crossing,L.(2001). Explaining groundwater hydrographs:Separating atypical rainfall events from time trends, Australian Journal of Soil Research 39(4),861-875.

Ferdowsian, R.Ryser,A.,George,R.,Bee,G. and Smart,R.(2002). Groundwater level reductions under lucerne depend on the landform and groundwater flow systems(local and intermediate) , Australian Journal of Soil Research 40(3),381-396.

Ferris, J.G. and Knowles,D.B.(1963). Fluctuations as basis for determining aquifer transmissibility. In:methods of determining permeability,transmissobility, and drawdown, U.S.Geol.Survey, Water Supply paper 1436-J.

Kim,S.J.,Hyun,Y. and Lee,K.(2005). Time series modeling for evaluation of groundwater discharge rates into an urban subway system, Geosciences Journal 9(1),15-22.

Peterson ,T.J. and Western A.W.(2011). Time-series modelling of groundwater head and its de-composition to historic climate periods, 34 ${ }^{\text {th }}$ IAHR World Congress,Brisbane,Australia,26 June-1 July 2011

Siriwardena,L., Peterson ,T.J. and Western A.W.(2011). A state-wide assessment of optimal groundwater hydrograph time series models, International Congress On Modelling and Simulation (MODSIM), Perth, Australia,12-16 December 2011

von Asmuth, J. R., Bierkens, M. F. P. and Maas, K.(2002). Transfer function-noise modeling in continuous time using predefined impulse reponse functions, Water Resources Research 46(1), 30-40.

von Asmuth, J. R., Maas, K., Bakker,M. and Petersen, J. (2008). Modeling time series of ground water head fluctuations subjected to multiple stresses, Ground Water 46(1), 30-40.

von Asmuth, J. R. and Bierkens,M. F. P.(2005). Modeling irregularly spaced residual series as a continuous stochastic process, Water Resources Research 41(12), W12404.

Yihdego,Y. and Webb,J.A. (2011) .Modelling of bore hydrograph to determine the impact of climate and land-use change in a temperate subhumid region of southeastern Asutralia, Hydrogeology Journal $19,877-887$ 